\title{
CONHECIMENTO DOS CIRURGIÕES-DENTISTAS DA REDE DE SAÚDE PÚBLICA DE FEIRA DE SANTANA SOBRE DOENÇA FALCIFORME
}

\author{
SILVA, Patrícia Camila Souza'; RODRIGUES Ana Áurea A.O.²; CARVALHO \\ Evanilda Souza de Santana ${ }^{3}$
}

1. Bolsista PROBIC/UEFS, Graduando em Odontologia, Universidade Estadual de Feira de Santana, e-mail: mila.ssilva@ outlook.com

2. Orientador, Departamento de Saúde, Universidade Estadual de Feira de Santana, email: aaarodrigues@homail.com

3. Participante do núcleo COGITARE, Departamento de Saúde, Universidade Estadual de Feira de Santana, e-mail: evasscarvalho@yohoo.com

\section{INTRODUÇÃO}

O termo Doença Falciforme (DF) engloba um grupo de anemias hemolíticas hereditárias que têm em comum a presença de hemoglobina $\mathrm{S}$ dentro da hemácia e representa a enfermidade hereditária mais prevalente no mundo (FERNANDES, 2016). Nesse grupo, destaca-se a Anemia Falciforme (AF), que apresenta importância clínica, hematológica, bioquímica e epidemiológica e que devido à sua morbidade e alto índice de mortalidade, tem sido apontada como uma questão de saúde pública (FREITAS, 2018). A falcização das hemácias ocasiona encurtamento da vida média dos glóbulos vermelhos, fenômenos de vaso-oclusão e episódios de dor e lesão de órgãos, incluindo o sistema estomatognático e suas estruturas anexas (DANTAS; SANCHEZ, 2016). A ocorrência de vaso-oclusões, principalmente em pequenos vasos, representa o evento fisiopatológico determinante na origem da maioria dos sinais e sintomas presentes no quadro clínico dos pacientes com doença falciforme, tais como as crises álgicas, úlceras de membros inferiores, síndrome torácica aguda (STA), sequestro esplênico, priapismo, necrose asséptica do fêmur, acidente vascular encefálico (AVE), entre outros (ASNANI; REID, 2015).

Feira de Santana é a segunda maior cidade da Bahia com casos de Doença Falciforme, cuja distribuição espacial, segundo trabalho publicado por Alves em 2012, ocorre da seguinte forma: as maiores frequências foram para as localidades do Tomba 12.6\%, Campo Limpo 9\%, Humildes 5.8\%, Jaíba 4\% e Matinha com 3.6\%. Na distribuição, oriundas da sede do município, segundo bairro e média de idade; as maiores frequências foram para os bairros do Tomba, $15.5 \%$ ( de idade $=19.9$ ) e Campo Limpo, $11 \%$ ( de idade $=20.4$ ). Dentre as localidades da área rural, as maiores frequências foram para os Distritos de Humildes $31 \%$ ( de idade $=21.1$ ), Jaiba $21.4 \%$ ( de idade $=13.2)$ e Matinha $19 \%($ de idade $=17.5)$.

O indivíduo portador de Doença Falciforme merece cuidados especiais durante toda vida, em virtude de possíveis comprometimentos em órgãos vitais. Esta desordem apresenta manifestações e complicações bucais que devem ser reconhecidas pelo cirurgião-dentista, para a escolha da conduta adequada nos cuidados com a saúde bucal. Diante do exposto o objetivo geral dessa pesquisa é avaliar o conhecimento sobre Doença Falciforme dos cirurgiões-dentistas que atuam nas Unidades de Saúde da Família na rede de atenção à saúde do município de Feira de Santana.

\section{MATERIAL E MÉTODOS OU METODOLOGIA}

Trata-se de um estudo quantitativo, descritivo, de caráter exploratório, de corte transversal. O campo de estudo foi o centro da região metropolitana de Feira de Santana. No cenário de estudo estão as Unidades de Saúde da Família (USF), das zonas 
urbana e rural do município, que possuem o programa Estratégia Saúde da Família (ESF) com cirurgião-dentista. O grupo de estudo é constituído por Cirurgiões-dentistas (CD) que atuam nas USF, totalizando 44 profissionais. Como critério de inclusão o profissional deverá ser funcionário das USF, das zonas urbana ou rural do município, que participam do programa ESF. No critério de não inclusão constam os CD que não atuam nas USF do município e os que não concordarem em participar da pesquisa.

$\mathrm{O}$ instrumento de coleta de dados utilizado foi um questionário que aborda questões sócio demográficas e dados a respeito do conhecimento e da conduta dos participantes da pesquisa com relação à DF. O questionário foi aplicado pelas pesquisadoras nas USF e permaneceram na presença dos CD para evitar qualquer tipo de consulta. Não houve nenhuma forma de intervenção dos pesquisadores que pudesse influenciar nas respostas. Os dados coletados, após conclusão da coleta, serão analisados pelo Statistical Package for the Social Sciences (SPSS) versão 22.0 e uma análise descritiva dos dados será realizada através da distribuição das frequências absolutas e relativas das variáveis do estudo. Pretende-se também realizar uma análise exploratória das variáveis, analisando a distribuição conjunta, a fim se observar se há existência de associação entre sexo, tempo de formação do cirurgião dentista; a universidade de procedência; conhecimento sobre a doença falciforme e realização de atendimento odontológico em paciente com doença falciforme. Neste resumo será apresentada uma análise descritiva das variáveis estudadas, por meio de gráficos construídos usando-se o programa Microsoft Excel, versão 2013.

\section{RESULTADOS E/OU DISCUSSÃO}

Diante das dificuldades encontradas no decorrer na pesquisa e da falta de conclusão da coleta de dados, apenas metade das unidades, de um total de 44 , foi pesquisada, restando 22 para o segundo semestre de 2018.

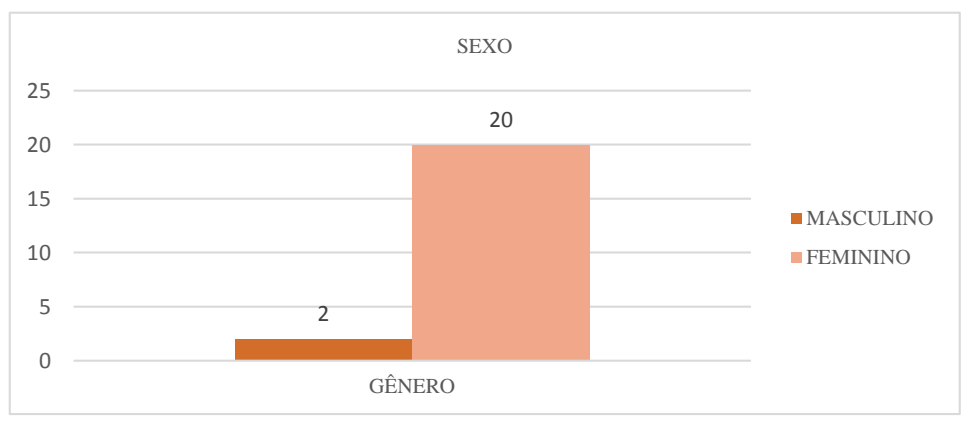

Figura 1. Distribuição por sexo dos 22 Cirurgiões-dentistas entrevistados nas Unidades da Saúde da Família, Feira de Santana, Bahia. 
Quanto a universidade de procedência observa-se que $17 \mathrm{CD}$ vieram de centro de formação público e 5 eram de centro de formação privado. Todos responderam esta pergunta de forma clara, não havendo respostas em branco no questionário.

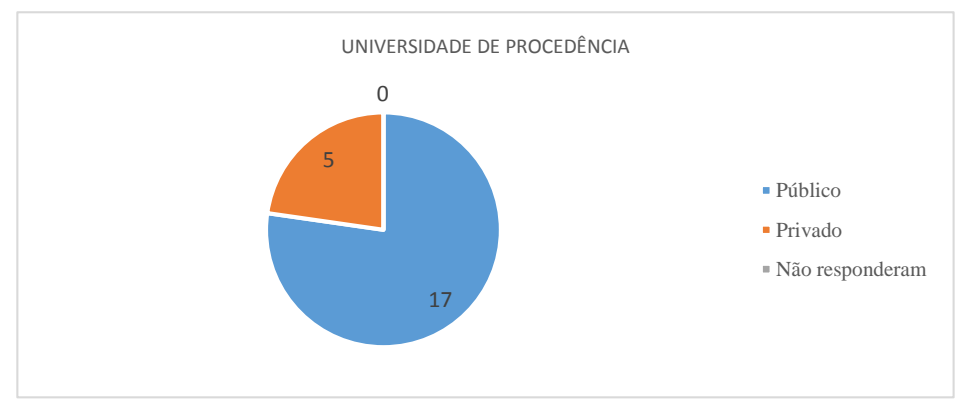

Figura 2. Distribuição por Universidade de procedência dos 22 cirurgiões-dentistas entrevistados nas Unidades da Saúde da Família, Feira de Santana, Bahia

Na variável de procedimentos realizados em pacientes com DF observa-se, que muitos não realizavam nenhum procedimento. Nas opções restauração em dente permanente, raspagem e alisamento radicular e exodontia em dentes decíduos houve coincidência na quantidade de procedimentos realizados. Vale ressaltar que no questionário havia possibilidade de um único dentista realizar mais de um tipo de procedimento, por este motivo que a quantidade observada na figura não corresponde ao número total da amostra de $22 \mathrm{CD}$.

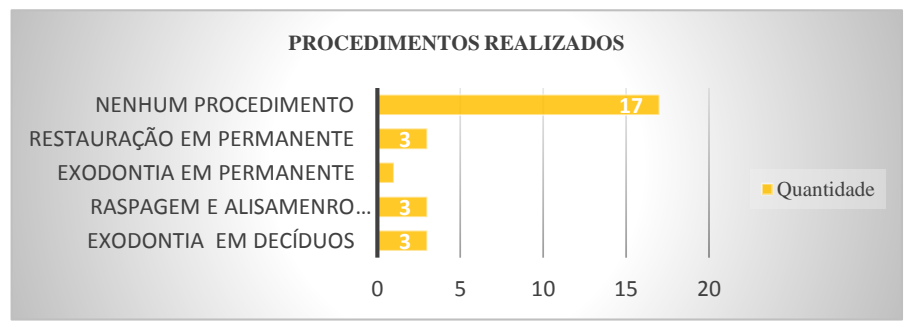

Figura 3. Distribuição por procedimentos realizados pelos 22 cirurgiões-dentistas entrevistados nas Unidades da Saúde da Família, Feira de Santana, Bahia.

Para avalição da variável - conhecimento sobre a doença falciforme - reuniu-se em tabela as perguntas existentes no questionário com as respostas do mesmo. Na Tabela 1 observa-se que responderam corretamente é maior que o número de $\mathrm{CD}$ que responderam de maneira equivocada ou não responderam. $\mathrm{O}$ critério utilizado para essa variável do conhecimento foi justamente o conhecimento científico sobre a origem da DF e manifestações orais. Na Tabela 2 evidencia-se que predomina a quantidade de dentistas que conhecem abordagens sobre a Doença Falciforme 


\begin{tabular}{|c|c|c|c|}
\hline QUESTÕES & $\begin{array}{l}\text { RESPOSTA } \\
\text { CORRETA }\end{array}$ & $\begin{array}{l}\text { RESPOSTA } \\
\text { ERRADA }\end{array}$ & $\begin{array}{c}\text { NÃO } \\
\text { RESPONDERAM }\end{array}$ \\
\hline Qual a causa da doença falciforme? & 22 & 0 & 0 \\
\hline A Doença Falciforme tem cura. & 20 & 2 & 0 \\
\hline $\begin{array}{l}\text { Tem diferença entre Doença Falciforme e } \\
\text { Anemia Falciforme? Se sim, qual? }\end{array}$ & 4 & 7 & 11 \\
\hline $\begin{array}{l}\text { Informe algumas manifestações clínicas desta } \\
\text { doença: }\end{array}$ & 13 & 1 & 8 \\
\hline
\end{tabular}

Tabela 1. Respostas do questionário aplicado aos 22 Cirurgiões-dentistas entrevistados nas Unidades da Saúde da Família, Feira de Santana, Bahia.

\begin{tabular}{|c|c|c|c|}
\hline QUESTÕES & $\begin{array}{l}\text { RESPOSTA } \\
\text { SIM }\end{array}$ & $\begin{array}{l}\text { RESPOSTA } \\
\text { NÃO }\end{array}$ & $\begin{array}{c}\text { NÃO } \\
\text { RESPODERAM }\end{array}$ \\
\hline $\begin{array}{l}\text { A Anemia falciforme é causada pela falta do } \\
\text { elemento ferro no organismo? }\end{array}$ & 7 & 15 & $\mathbf{0}$ \\
\hline Você já ouviu falar de Doença Falciforme? & 22 & $\mathbf{0}$ & $\mathbf{0}$ \\
\hline $\begin{array}{l}\text { Você tem na população adstrita algum paciente } \\
\text { com Doença Falciforme? }\end{array}$ & 7 & 10 & 5 \\
\hline $\begin{array}{l}\text { As infecções na cavidade oral podem precipitar as } \\
\text { crises dolorosas? }\end{array}$ & 16 & $\mathbf{0}$ & 6 \\
\hline $\begin{array}{l}\text { Pacientes com Anemia Falciforme precisam de } \\
\text { cuidados especiais? }\end{array}$ & 21 & 1 & $\mathbf{0}$ \\
\hline
\end{tabular}

Tabela 2. Respostas do questionário aplicado aos 22 Cirurgiões-dentistas entrevistados nas Unidades da Saúde da Família, Feira de Santana, Bahia.

\section{CONSIDERAÇÕES FINAIS}

Diante dos resultados deste estudo, mesmo não dispondo de toda coleta de dados, observa-se que os cirurgiões-dentistas da rede de Feira de Santana têm alguma informação sobre a Doença Falciforme, no entanto, realizam poucos procedimentos, apesar do registro de pacientes com doença falciforme em algumas áreas de abrangência das unidades estudadas.

\section{REFERÊNCIAS}

ALVES, R.J.C. Aspectos epidemiológicos da doença falciforme e sua distribuição espacial em feira de Santana entre 2010 e 2012. Dissertação Mestrado em Modelagem em Ciencias da Terra e do Ambiente da Universidade Estadual de Feira de Santana), Feira de Santana, 2012.

ASNANI, M.R; REID, M.E. Renal funcion in adult Jamaicans with homozygous sicke cell disease. Hematology; 20(7): 422-8, 2015 Aug. 
FERNANDES, M. L. M. F et al. Oral health-related quality of life of children and teens with sickle cell disease. São Paulo, v. 38, n. 2, p. 106-112, June 2016.

FREITAS, S.L.F; IVO M.L; FIGUEIREDO, M.S; GERK, M.A.S; NUNES, C.B, MONTEIRO, F.F. Quality of life in adults with sickle cell disease: an integrative review of the literature. Rev Bras Enferm [Internet]. 2018;71(1):195-205.

SANCHEZ, H. F; DANTAS, L. G. S. Proposta de atendimento em saúde bucal para portadores de anemia falciforme na atenção primária à saúde Rev. APS. 2016 out/dez; 19(4): 623 - 629.
Comentado [U1]: qual o periódico? 